\title{
Association between Serotonin Transporter-Linked Polymorphic Region and Escitalopram Antidepressant Treatment Response in Korean Patients with Major Depressive Disorder
}

\author{
Eun-Soo Won ${ }^{a}$ Hun-Soo Chang ${ }^{b}$ Hwa-Young Lee ${ }^{c}$ Byung-Joo Ham ${ }^{a}$ Min-Soo Lee ${ }^{a}$ b

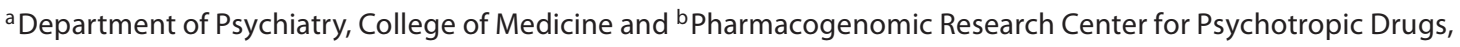 \\ Korea University, Seoul, and 'Department of Psychiatry, Soonchunhyang University Cheonan Hospital, \\ Cheonan City, Republic of Korea
}

\section{Key Words}

Major depressive disorder $\cdot$ Serotonin transporter-linked polymorphic region - Escitalopram treatment response

\begin{abstract}
Objective: Various studies have shown that short (s)/long (I) polymorphisms of the serotonin transporter-linked polymorphic region (5-HTTLPR) might predict treatment outcome to selective serotonin reuptake inhibitors. The purpose of this study was to evaluate the association between 5-HTTLPR and clinical response to escitalopram treatment in Korean subjects with major depressive disorder. Methods: One hundred and fifteen Korean patients diagnosed with major depressive disorder were evaluated during 8 weeks of escitalopram treatment at a dose of 5-20 mg/day. Patients were genotyped for 5-HTTLPR using polymerase chain reaction. Clinical symptoms were evaluated by the 21 -item Hamilton Depression Rating (HAMD-21) scale during the 8 weeks of treatment. Results: Therapeutic response to antidepressant escitalopram was better in s allele carriers (ss, sl) than in I allele homozygotes (II) at 8 weeks of treatment (OR $=6.24$, $p=0.026)$. The proportion of $s$ allele carriers in responders was higher than that in non-responders ( 96.6 vs. $85.7 \%$ ). The percentile decline in HAMD-21 in s allele carriers (59.86 \pm
\end{abstract}

3.23\%) was larger than that in HAMD-21 in I allele homozygotes ( $43.13 \pm 11.49 \% ; p=0.029)$. However, 5 -HTTLPR genotypes were not significantly associated with remission $(p>$ 0.05 ). Conclusions: Our results show that treatment response to escitalopram at 8 weeks was moderated by $5-\mathrm{HT}$ TLPR, with better response rates for $s$ allele carriers than for I allele homozygotes. Although the role of 5-HTTLPR as a definite predictor of selective serotonin reuptake inhibitor treatment response cannot be confirmed from current results, they do suggest a trend for better response in s allele carriers.

Copyright $\odot 2012$ S. Karger AG, Basel

\section{Introduction}

The human gene encoding the serotonin transporter (5-HTT) is located on chromosome 17q11.1-17q12, spans $31 \mathrm{~kb}$ and consists of 14 exons [1]. The primary molecular target for selective serotonin reuptake inhibitors (SSRIs) is 5 -HTT, which is responsible for serotonin reuptake at the terminals and cell bodies of serotonergic neurons [2]. In other words, the first step of SSRI action is to inhibit 5-HTT and thus modulate serotonergic activity [1]. Therefore, when searching for a genetic predictor of SSRI

\section{KARGER \\ Fax +41613061234 E-Mail karger@karger.ch} www.karger.com

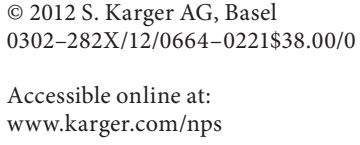


response, the 5-HTT gene (SLC6A4) is the natural candidate, as it encodes the molecular target of SSRI antidepressants [3]. One of the polymorphic sites in this gene is an insertion/deletion in the $5^{\prime}$-flanking promoter region (serotonin transporter-linked polymorphic region, 5-HTTLPR) [4], which has attracted much interest and has been intensively studied [5]. 5-HTTLPR has been the most widely studied in psychiatric genetics for its high number of effects [6], and its association with SSRI efficacy is of particular interest [1].

A number of polymorphisms have been proposed to modulate the functionality of 5-HTTLPR: single nucleotide polymorphisms rs25531 and rs2020933, and a 17-bp variable tandem repeat in the second intron (STin2) [3]. rs25531 in particular has been shown to modulate the effect of 5-HTTLPR on transcription efficacy [7]. However, the functionality of this single nucleotide polymorphism has not been consistently replicated, and it is still unclear whether the recoding of 5-HTTLPR is warranted [8-10]. Therefore, in the present study, the association of SSRI treatment response with 5-HTTLPR was evaluated independently from rs 25531.

5-HTTLPR, the common length polymorphism constituted by a deletion of $44 \mathrm{bp}$ in the promoter region [8], is an insertion/deletion polymorphism that results in a short (s) versus long (l) polymorphism [11]. The l allele of 5-HTTLPR has a 44-bp insertion of tandem repeat elements in the promoter region. The s allele lacks this 44-bp insertion [12]. The association between 5-HTTLPR and antidepressant treatment response has been investigated by a large number of studies, but findings have not always been consistent [13-19].

The 1 and $\mathrm{s}$ variants of the promoter polymorphism have been reported to have functional differences in modulating transcription of the 5-HTT gene as well as subsequent 5-HTT availability [20]. These allele-specific functional differences have previously been confirmed in human tissues including the brain $[12,21]$. The l allele has been associated with more efficient transcription [22], whereas the s allele is shown to have a 3- to 4 -fold lower 5 -HT uptake function in lymphoblasts due to reduced transcriptional efficiency [12]. However, other in vivo studies reported that 5 -HT binding did not significantly differ among s/s, s/l and 1/l groups in postmortem brain samples with the use of autoradiography [23], and that there was no effect of the 5-HTTLPR genotype upon 5-HTT binding with the use of SPECT [24]. Recently, another study also reported that 5-HTT binding in vivo was not significantly different among the 5-HTTLPR genotypes [25].
Although the 1 allele has been associated with better response to SSRI antidepressants in many studies [13], and significant associations between the long variant and good treatment response have been reported among studies performed in Caucasian populations, other studies performed on different ethnic populations did not confirm these findings $[26,27]$. In white populations, depressed patients with the 1 allele carriers of 5-HTTLPR have generally shown a greater response to SSRIs than those with homozygous $s$ alleles [13-16, 28]. However, significant heterogeneity of 5-HTTLPR effect was reported in non-European populations [29], and studies carried out on Japanese and Korean populations report an association in the opposite direction of previous studies carried out on Caucasian populations [18, 19]. Also, results from the largest meta-analysis of the effect of 5-HTTLPR polymorphisms on response or remission to antidepressant medication, which included data obtained from 28 studies with 5,408 participants, showed no significant effect of the biallelic polymorphism on response to SSRI medication [30].

Based on the results of prior studies, 5-HTTLPR seems to influence antidepressant treatment response, although the direction of such influence has not yet been clarified. Therefore, the primary aim of this study was to clarify the association of 5-HTTLPR and treatment response to SSRIs in Korean patients with major depressive disorder.

\section{Methods}

Subjects

In- and outpatients, aged 18-75 years, were recruited by the Pharmacogenomic Research Center for Psychotropic Drugs at the Department of Psychiatry, Korea University College of Medicine. All subjects were self-identified Koreans, and ethnic origin was further ascertained by confirming the ethnicity of three generations of the patients' families. Trained psychiatrists examined all potential subjects using the Structured Clinical Interview for the fourth revision of the Diagnostic and Statistical Manual of Mental Disorders (DSM-IV) [30] and the Korean version of the Diagnostic Interview for Genetic Studies [31]. Only subjects with a minimum score of 18 on the 21-item Hamilton Depression Rating (HAMD-21) scale [32] entered the study. The presence of psychotic symptoms was assessed, and none of the subjects enrolled in the study were presenting any psychotic symptoms.

Subjects with primary or comorbid psychiatric diagnoses other than major depressive disorder based on DSM-IV criteria, such as bipolar disorder, schizophrenia, schizoaffective disorder, rapid cycling bipolar disorder, dementia, alcohol/substance dependence and clinically relevant personality disorders, were excluded from the study. Subjects with physical conditions of clinical relevance, such as seizures, brain lesions, cardiac problems, liver/ kidney failures, pregnancy, lactations, and abnormal laboratory 
Table 1. Demographic characteristics in the major depressive disorder intention-to-treat group

\begin{tabular}{|c|c|c|c|c|}
\hline & \multicolumn{3}{|c|}{ 5-HTTLPR genotype $(\mathrm{n}=115)$} & \multirow[t]{2}{*}{$\mathrm{p}$ value } \\
\hline & ss & $\mathrm{sl}$ & 11 & \\
\hline Patients & 70 & 35 & 10 & $0.079^{1}$ \\
\hline Age, years & $46.17 \pm 1.87$ & $45.94 \pm 2.85$ & $47.80 \pm 5.41$ & 0.948 \\
\hline Onset age, years & $39.11 \pm 2.07$ & $41.69 \pm 2.90$ & $42.70 \pm 5.31$ & 0.688 \\
\hline Males & $11(15.7)$ & $5(14.3)$ & 0 & 0.405 \\
\hline Previous history of depression & $52(74.3)$ & $25(71.4)$ & $8(80.0)$ & 0.857 \\
\hline Family history of depression & $10(14.3)$ & $6(17.1)$ & $1(10.0)$ & 0.839 \\
\hline Family history of other psychotic disease & $8(11.4)$ & $3(8.6)$ & 0 & 0.723 \\
\hline Suicide attempt & $3(4.3)$ & $2(5.7)$ & 0 & 0.736 \\
\hline Baseline HAMD-21 score & $21.54 \pm 0.44$ & $22.91 \pm 0.68$ & $22.04 \pm 0.36$ & 0.208 \\
\hline Escitalopram dosage, mg & $10.50 \pm 2.43$ & $10.29 \pm 1.69$ & $10.00 \pm 0.00$ & 0.738 \\
\hline
\end{tabular}

Data are means $\pm \mathrm{SE}$, or number of cases, with percentages in parentheses.

baseline values, were excluded. Patients who were receiving psychotropic medications were subjected to a 2 -week washout period. The protocol was approved by the ethics review board of Korea University College of Medicine, and signed informed consent was obtained from all participants.

\section{Clinical Assessment}

A total of 115 patients were enrolled from March 2009 through June 2011. During the treatment period of the study, all subjects took escitalopram (lexapro tablet) daily at a dose of 5-20 mg/day for 8 weeks. Dose titration was completed within 2 weeks. Doses were titrated into the usual clinical range based on initial tolerability and adverse effects. A 1- to 2-mg dose of lorazepam could be prescribed at bedtime for insomnia. Psychotropic drugs such as antipsychotics and mood stabilizers were not permitted. Patients were seen by a psychiatrist who monitored their adverse events by the UKU Side Effect Rating Scale 16 [33] at weeks 0, 1, 2, 4 and 8. The HAMD-21 was administered by a single trained rater. The rater and genotyper were blinded to the hypothesis of the study. Severity of depression was assessed using HAMD-21 and the Clinical Global Impression scale on weeks $0,1,2,4$ and 8 . Responders were defined as subjects exhibiting a $50 \%$ decrease from the baseline score of the HAMD-21 total score at 8 weeks. Remitters were defined as subjects having a HAMD-21 total score of $\leq 7$ at 8 weeks [34].

One hundred and fifteen patients were initially enrolled and a total of 74 patients completed the 8 -week treatment trial. Fortyone patients dropped out of the study. Last observation carried forward analysis was performed for the missing data in HAMD21 scores for these 41 dropouts.

\section{Genetic Analysis}

Venous blood was drawn from each subject using a protocol approved by the Ethics Committee of the Korea University Medical Center. DNA was extracted from peripheral blood and a polymerase chain reaction was performed according to a previously described protocol [20], with the sense primer 5'-ACT CTG GAG AGC GTG AAT- $3^{\prime}$ and the antisense primer $5^{\prime}$-ATA CTG TCA CAC ACG CTC-3'.

Association between 5-HTTLPR and

Escitalopram Treatment Response

\section{Statistical Analysis}

The Hardy-Weinberg equilibrium for the 5-HTTPLR polymorphism was tested using a $\chi^{2}$ test. The genetic association of the single nucleotide polymorphism was analyzed using multiple logistic regression and generalized linear model type III for categorical data and continuous variables, respectively, controlling for age and sex as covariates. A p value $\leq 0.05$ was regarded as statistically significant. All statistical analyses were performed using SPSS version 10.0 (SPSS Inc., Chicago, Ill., USA). Given the lack of unequivocal data for 5-HTTLPR genotype pooling [1], codominant, dominant and recessive genetic models were tested assuming the 1 allele to be associated with a reduced treatment response compared to the s allele: s/l genotype patients versus homozygous for s allele and l allele patients (s/s, l/l genotype patients), 1 allele carrier patients (1/l, s/l genotype patients) versus non 1 allele carrier patients (s/s genotype patients), and homozygous for 1 allele patients ( $1 / 1$ genotype patients) versus s allele carrier patients (s/s, s/l genotype patients).

\section{Results}

\section{Clinical Characteristics of Study Subjects and \\ Hardy-Weinberg Equilibrium for the 5-HTTLPR}

Table 1 summarizes patient data for mean age, age at onset, gender, previous history of depression, family history of depression or other psychotic diseases, frequency of suicide attempts, escitalopram dosage and baseline HAMD-21 scores. None of these parameters differed significantly among the three 5-HTTLPR genotypes (s/s, s/1 and $1 / 1) \cdot \chi^{2}$ tests applied to the three genotype frequencies revealed that the subjects were in Hardy-Weinberg equilibrium $\left(\chi^{2}=3.08, p=0.079\right)$. In addition, baseline HAMD21 scores did not differ according to 5-HTTLPR genotypes 

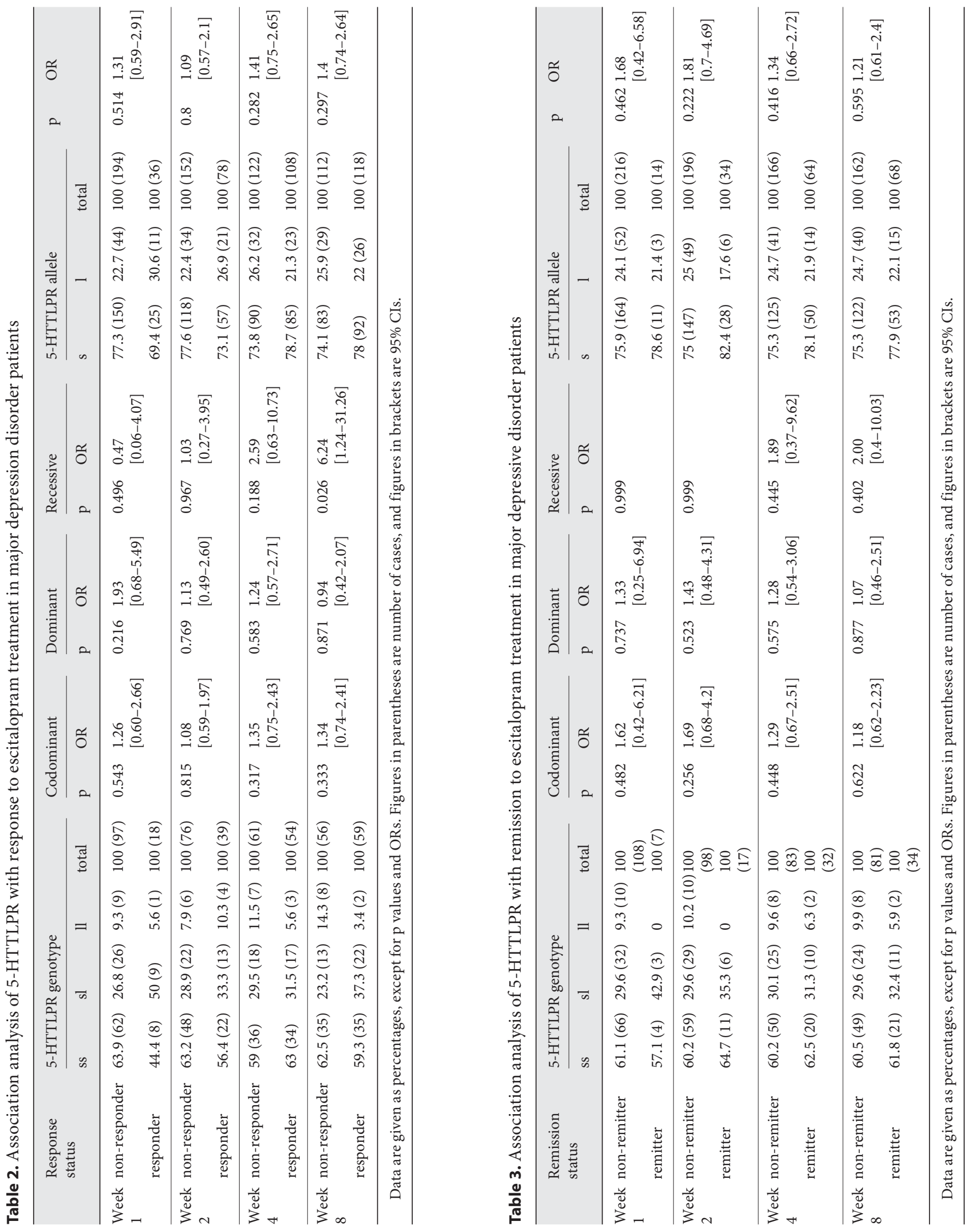
or alleles. Among the 41 patients who dropped out of the study, 4 patients discontinued treatment based on intolerable adverse effects. One patient failed to attend scheduled clinic visits due to economic problems. Fifteen patients discontinued treatment due to symptom improvement according to chartings; however, the HAMD-21 total scores of 5 patients were not significantly decreased to be considered as response or remission. Twenty-one patients discontinued treatment due to insufficient symptom improvement according to chartings. The clinical characteristics of the dropouts did not differ significantly from the completers (data not shown). Also, the 5-HTTLPR genotype of the dropouts did not differ significantly according to reasons for dropouts, which were discontinuation due to symptom improvement, discontinuation due to insufficient symptom improvement and discontinuation due to side effects (Fisher's exact test, $\mathrm{p}=0.486$ ).

\section{Association between 5-HTTLPR and Escitalopram}

Treatment Response in Major Depressive Disorder

Patients

We evaluated the relationship between 5-HTTLPR and escitalopram treatment response. As shown in table 2, 5-HTTLPR genotypes were associated with treatment response at 8 weeks of escitalopram treatment. The therapeutic response to antidepressant escitalopram was better in s allele carriers than in the $1 / 1$ genotype patients at 8 weeks $(\mathrm{OR}=6.24, \mathrm{p}=0.026,95 \% \mathrm{CI}=1.24-31.26$ ). The proportion of s allele carriers in responders was higher than that in non-responders (96.6 vs. 85.7\%). As shown in figure 1, the percent decline in HAMD-21 in patients bearing the s allele $(59.86 \pm 3.23 \%)$ was larger than that in 1 allele homozygotes at 8 weeks of escitalopram treatment $(43.13 \pm 11.49 \% ; \mathrm{p}=0.029)$.

\section{Association between 5-HTTLPR and Remission Status} by Escitalopram Treatment

As the association between 5-HTTLPR genotype and response to escitalopram treatment was observed, we also evaluated the relationship between 5-HTTLPR and remission status. However, as shown in table 3, 5-HTTLPR genotypes were not significantly associated with remission $(\mathrm{p}>0.05)$.

\section{Discussion}

To our knowledge, this study was the first to investigate the relationship between 5-HTTLPR and antidepressant treatment response to escitalopram monotherapy in

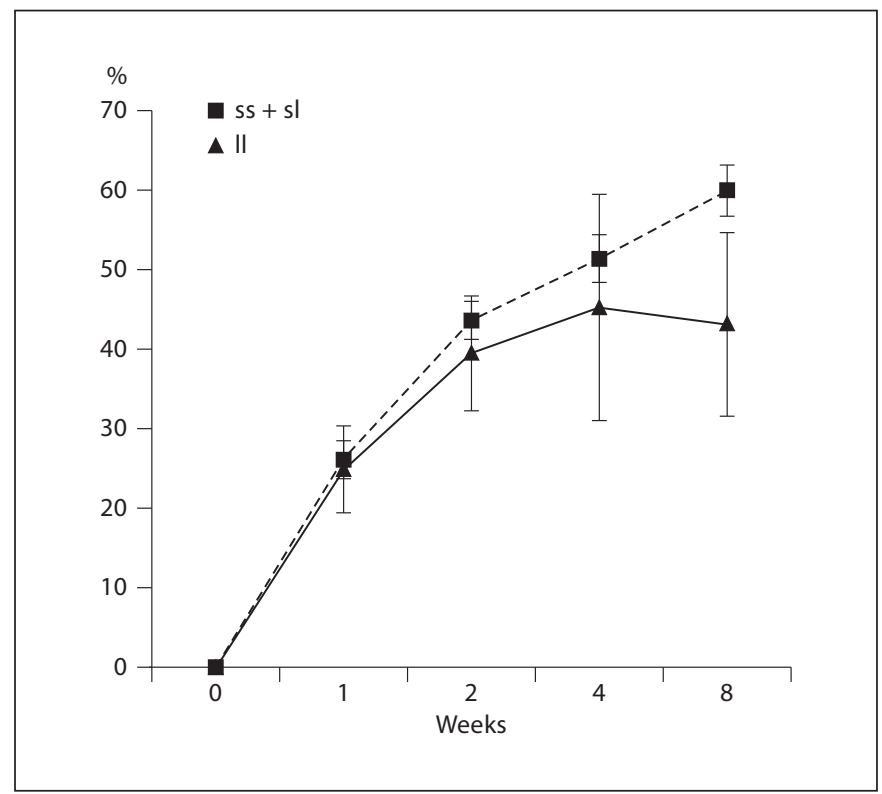

Fig. 1. Percent decline in HAMD-21 scores with escitalopram treatment. The 11 genotype versus s allele carriers.

a single ethnic group of Koreans diagnosed with major depressive disorder, for a period of 8 weeks. Our analysis showed that treatment response in 8 weeks was moderated by 5 -HTTLPR in the recessive model, with better response rates for $\mathrm{s}$ allele carriers than for 1 allele homozygotes. Similar results were observed in a meta-analysis of 15 studies including data of 1,435 subjects which observed a significant association of the s/s variant of 5-HTTLPR with the remission rate and both $\mathrm{s} / \mathrm{s}$ and $\mathrm{s} / \mathrm{l}$ variants with the response rate, by testing both dominant and recessive hypotheses: $1 / 1$ versus $1 / \mathrm{s}-\mathrm{s} / \mathrm{s}$ and $1 / 1-1 / \mathrm{s}$ versus $\mathrm{s} / \mathrm{s}$ [1]. The favorable allele for response to SSRI drugs in Korean depressed patients was also the s allele, as shown in a previous study [29]. However, another study conducted on 121 Chinese patients diagnosed with major depression revealed that the $1 / 1$ genotype had a significantly better response to SSRI (fluoxetine) when compared with s allele carriers [35].

A previous systematic review of the literature on the influence of polymorphisms in the serotonin transporter gene on SSRI response revealed that in Caucasian patients, response to SSRIs seemed less favorable for patients with the s/s genotype than for those with the s/l and $1 / 1$ genotypes. On the other hand, among Asian patients, effects in both directions were observed [27]. Another meta-analysis observed a significant association of the s/s variant of 5-HTTLPR with the remission rate and both 
$s / s$ and $s / l$ variants with the response rate. However, a significant heterogeneity was present in Asian samples [1].

There are some speculations about why such discrepancies among Asians and Caucasians exist. Different allele frequencies may be a strong cause of heterogeneity. The s allele is known to be present in $42 \%$ of Caucasians whereas it is known to be present in 79\% of Asians [36]. The 1 allele frequency in Korean and Japanese populations is about $25 \%[18,19,37,38]$, compared with about $55 \%$ in white populations $[13-15,39]$. If the favorable allele were to be the 1 allele, as indicated in many studies carried out on Caucasians, a low rate of response in Asians to SSRIs should be expected, as there are much less 1 allele carriers in the Asian population. However, it is a consistent finding that $60-70 \%$ of depressed patients respond to SSRI drugs in multicenter clinical trials regardless of the ethnic group [40-43].

A previous study reported that the $V_{\max }$ value of 5-HTT in peripheral platelets was higher in patients with the s/s genotype than in those with the s/l or 1/l genotypes of 5-HTTLPR [7]. This suggests that allelic variation of the 5-HTT gene affects the phenotypic expression of 5-HTT in human platelets, which may be linked with phenotypic heterogeneity in the antidepressant responsiveness in depressed patients. Results of a meta-analysis indicate that alterations in 5-HT signaling associated with the 5-HTTLPR appear to contribute significantly to the variability of amygdala activation [19]. However, the direction of this association seemed to be influenced by genetic background, as the studies reporting greater amygdala activation in 1 allele carriers were comprised largely of individuals of East Asian ancestry rather than of Caucasians [44].

Some speculate that 5-HTTLPR is linked with unknown functional variants. It may be an associated marker in linkage disequilibrium with a functional site, rather than a functional polymorphism itself. The authentic functional sequence variants may be in strong linkage disequilibrium with the 1 allele in Caucasians and also in linkage disequilibrium with the s allele in Koreans. Also, different ethnic populations may have other polymorphisms in linkage disequilibrium with 5-HTT polymorphisms [29]. It is possible that the discrepancies are a result of the influence of another polymorphism that is in population-specific linkage disequilibrium with the 5-HTTLPR [45].

Many studies conducted on Caucasians show a similar direction of effect, with the 1 allelic variation of 5-HTTLPR being reported as a predictor of better antidepressant treatment response [13-16, 28]. However, a number of studies conducted on Caucasian-dominant groups did not show similar results, with the s allele being associated with better treatment response/remission [46, 47], or with the insertion/deletion genotype having no effect on treatment $[48,49]$. Studies conducted on Asian patients have shown even more opposing results on which variant is the favorable one for antidepressant treatment $[18,19,35]$. The reason for the large amount of heterogeneity in the Asian population is currently not well understood. Different dosages of SSRIs and different lengths of assessment of the previous studies may have contributed to such heterogeneity. Also, other genetic explanations are being sought. A wider list of polymorphisms should be investigated to achieve a better resolution given that other control regions may be present for the 5-HTT expression, not to mention possible enhancers or silencers located in other regions far from the gene locus [1].

A number of polymorphisms have been found in the proximity of the insertion/deletion locus, such as rs 25531 , rs25532, rs2020933 and a 17-bp variable tandem repeat in the second intron (STin2) [50-53], and have been proposed to modulate the functionality of 5-HTTLPR [3]. The rs25531, which is located in the sixth repeat of the 5-HTTLPR outside the deleted segment [3], can co-occur with either the long or short variant of the 5-HTTLPR [9]. The rs25531 results in an A to G substitution [54], and the minor $G$ allele of the rs 23551 creates a consensus binding sequence for the transcription factor AP-2, which is involved in antidepressant action [55]. It has been proposed that the rs 25531 influences the functionality of the serotonin transporter, and recoding of 5-HTTLPR long alleles based on the rs 25531 has been suggested [5]. The G allele of rs 25531 is in phase with the 5-HTTLPR 1 allele and mitigates transcriptional efficacy to a higher degree than the 5-HTTLPR s allele [7]. Therefore, modulation of the 5-HTTLPR by rs25531 results in haplotypes with high $\left(l_{A}\right)$ or low $\left(l_{G}, s_{A}\right.$ or $\left.s_{G}\right)$ transcriptional efficacy $[5,10]$. As $l_{G}$ drives expression nearly equivalently to $s$, studies that include many $l_{G}$ alleles within sl and 11 genotypes may underestimate the effect of 5-HTTLPR [5].

Also, SLC6A4 is not the only genetic influence that alters drug response. Other candidate genes such as serotonin receptor genes, brain-derived neurotrophic factor, P-glycoprotein, G-protein, TPH1/TPH2, MAO-A, noradrenaline transporter genes, FKBP5 or cytochrome P450 genes are being considered to influence antidepressant response [56]. The influence of such other genes may be the reason why the association studies, concerning 5-HTTLPR and drug response, have produced conflicting results. 
Escitalopram was the choice of drug in this study due to the following aspects. Among the many SSRIs, escitalopram has been distinguished by being the most selective inhibitor of the serotonin transporter molecule [57]. In other words, escitalopram shows high selectivity of serotonin reuptake inhibition and has the highest affinity for the human serotonin transporter among SSRIs currently used [58]. Escitalopram also has little cytochrome $\mathrm{P}$ or P-glycoprotein inhibition, thus having a low potential for drug-drug interactions [59], and its capability of inhibiting serotonin reuptake without appreciably inhibiting the uptake of noradrenaline or dopamine makes it a perfect target for pharmacogenetic studies [60].

The timing of onset of clinical improvement with the SSRIs has been studied less extensively than with the older-generation antidepressants [61]. However, it was previously reported that non-responders at weeks 4 and 6 were less likely to become responders at week 8 , whereas early responders at weeks 2 or 4 were more likely to be responders at week 8 [62]. Also, data from a study carried out on 182 outpatients with major depression suggested that more than half of eventual responders to SSRI treatment at 8 weeks start to respond by week 2 ; over $75 \%$ start to respond by week 4 . Conversely, the lack of onset of response at 4-6 weeks was associated with about a $73-88 \%$ chance that patients would not have an onset of response by 8 weeks [61]. Therefore, based on these previous findings, we decided to observe treatment response to escitalopram for a duration of 8 weeks in this study.

A limitation of this study is that the total number of enrolled patients is relatively low, with an even smaller number of 1 allele homozygotes; thus, our observations may differ when analyzed with a larger population. Further, we cannot exclude the presence of a population stratification bias. However, as the Korean population is characterized by a relatively high degree of genetic homogeneity, we may safely conclude that such a stratification bias is unlikely in our sample. Also, this study was conducted with a semi-naturalistic design, in which the antidepressant was titrated to a final dosage based on therapeutic responses or intolerable adverse effects. Another limitation of this study is the absence of a placebo-treated group. Because we do not know the rate of nonspecific or non-drug attributable response, we cannot determine from the present data whether subgroups with high rates of response reflect specific drug effects or combinations of drug effects with high nonspecific response rates.

Despite these limitations, this study demonstrates a possibility that response to SSRI antidepressants may be associated with monoamine transporter gene polymor- phisms. Considering the relatively small number of enrolled patients and 1 allele homozygotes, and the fact that no significant association of 5-HTTLPR genotypes with remission was observed, the role of 5-HTTLPR as a definite predictor of SSRI treatment response cannot be confirmed from the results of this study. However, the results do suggest a trend of better response in $s$ allele carriers.

An association between 5-HTTLPR genotypes and treatment response being observed, but not with remission, could be due to the following factors. As responders were defined as subjects exhibiting a $50 \%$ decrease from the baseline score of the HAMD-21 total score, and remission was defined as subjects having a HAMD-21 total score of $\leq 7$ [34], a longer period of time may be needed for individuals to achieve a state of remission compared to a state of response. If subjects were to be observed for a longer duration than 8 weeks, which was considered sufficient enough to observe the response status in this study [61, 62], 5-HTTLPR genotypes may also show an association with remission.

Also, antidepressant treatment response and remission is influenced by many factors other than 5-HTTLPR genotypes, and SLC6A4 is not the sole genetic regulator of antidepressant treatment response and remission. Therefore, we consider 5-HTTLPR genotypes to be one among many contributing factors, with a trend of better response in s allele carriers, but not as a definite predictor of antidepressant treatment response and remission. As a state of response is more readily achieved than a state of remission, the contribution of 5-HTTLPR genotypes may be evident earlier in the former rather than in the latter. Therefore, there is a strong possibility that an apparent relationship between s allele 5-HTTLPR genotype in Koreans and better SSRI treatment response will be presented when treatment response is observed in a larger patient group.

In conclusion, our data demonstrate a trend of better response in s allele carriers to escitalopram treatment. Other genes are expected to influence this complex trait, and comprehensive knowledge on this matter may enable the clinical use of genetic profiling as a predictor, which allows the identification of the best therapeutic tool and the avoidance of lengthy treatment trials.

\section{Acknowledgements}

This research was performed as part of a master thesis (in Medicine) by Dr. E.-S. Won. 


\section{References}

$\checkmark 1$ Serretti A, Kato M, De Ronchi D, Kinoshita T: Meta-analysis of serotonin transporter gene promoter polymorphism (5-HTTLPR) association with selective serotonin reuptake inhibitor efficacy in depressed patients. Mol Psychiatry 2007;12:247-257.

-2 Blakely RD, Ramamoorthy S, Schroeter S, Qian Y, Apparsundaram S, Galli A, DeFelice LJ: Regulated phosphorylation and trafficking of antidepressant-sensitive serotonin transporter proteins. Biol Psychiatry 1998; 44:169-178.

3 Huezo-Diaz P, Uher R, Smith R, Rietschel M, Henigsberg N, Marusic A, Mors O, Maier W, Hauser J, Souery D, Placentino A, Zobel A, Larsen ER, Czerski PM, Gupta B, Hoda F, Perroud N, Farmer A, Craig I, Aitchison KJ, McGuffin P: Moderation of antidepressant response by the serotonin transporter gene. Br J Psychiatry 2009;195:30-38.

$\checkmark 4$ Michaelovsky E, Frisch A, Rockah R, Peleg L, Magal N, Shohat M, Weizman R: A novel allele in the promoter region of the human serotonin transporter gene. Mol Psychiatry 1999;4:97-99.

5 Hu XZ, Lipsky RH, Zhu G, Akhtar LA, Taubman J, Greenberg BD, Xu K, Arnold PD, Richter MA, Kennedy JL, Murphy DL, Goldman D: Serotonin transporter promoter gain-of-function genotypes are linked to obsessive-compulsive disorder. Am J Hum Genet 2006;78:815-826.

6 Serretti A, Calati R, Mandelli L, De Ronchi D: Serotonin transporter gene variants and behavior: a comprehensive review. Curr Drug Targets 2006;7:1659-1669.

$\checkmark 7$ Bozina N, Jovanovic N, Podlesek A, Rojnic Kuzman M, Kudumija Slijepcevic M, Roguljic A, Dimitrovic A, Bozina T, Lovric J, Ljubic H, Medved V: Suicide ideators and attempters with schizophrenia - the role of 5-HTTLPR, rs25531, and 5-HTT VNTR intron 2 variants. J Psychiatr Res 2012;46:767-773.

$\checkmark 8$ Uher R, McGuffin P: The moderation by the serotonin transporter gene of environmental adversity in the aetiology of mental illness: review and methodological analysis. Mol Psychiatry 2008;13:131-146.

9 Wendland JR, Martin BJ, Kruse MR, Lesch KP, Murphy DL: Simultaneous genotyping of four functional loci of human SLC6A4, with a reappraisal of 5-HTTLPR and rs25531. Mol Psychiatry 2006;11:224-226.

-10 Martin J, Cleak J, Willis-Owen SA, Flint J, Shifman S: Mapping regulatory variants for the serotonin transporter gene based on allelic expression imbalance. Mol Psychiatry 2007;12:421-422.

-11 Lenze EJ, Goate AM, Nowotny P, Dixon D, Shi P, Bies RR, Lotrich FK, Rollman BL, Shear MK, Thompson PA, Andreescu C, Pollock BG: Relation of serotonin transporter genetic variation to efficacy of escitalopram for generalized anxiety disorder in older adults. J Clin Psychopharmacol 2010;30:672-677.
12 Lesch KP, Bengel D, Heils A, Sabol SZ, Greenberg BD, Petri S, Benjamin J, Muller CR, Hamer DH, Murphy DL: Association of anxiety-related traits with a polymorphism in the serotonin transporter gene regulatory region. Science 1996;274:1527-1531.

13 Smeraldi E, Zanardi R, Benedetti F, Di Bella D, Perez J, Catalano M: Polymorphism within the promoter of the serotonin transporter gene and antidepressant efficacy of fluvoxamine. Mol Psychiatry 1998;3:508-511.

14 Pollock BG, Ferrell RE, Mulsant BH, Mazumdar S, Miller M, Sweet RA, Davis S, Kirshner MA, Houck PR, Stack JA, Reynolds CF, Kupfer DJ: Allelic variation in the serotonin transporter promoter affects onset of paroxetine treatment response in late-life depression. Neuropsychopharmacology 2000; 23:587-590.

-15 Zanardi R, Serretti A, Rossini D, Franchini L, Cusin C, Lattuada E, Dotoli D, Smeraldi E: Factors affecting fluvoxamine antidepressant activity: influence of pindolol and 5-HTTLPR in delusional and nondelusional depression. Biol Psychiatry 2001;50:323330.

16 Rausch JL, Johnson ME, Fei YJ, Li JQ, Shendarkar N, Hobby HM, Ganapathy V, Leibach FH: Initial conditions of serotonin transporter kinetics and genotype: influence on SSRI treatment trial outcome. Biol Psychiatry 2002;51:723-732.

17 Arias B, Catalan R, Gasto C, Gutierrez B, Fananas L: 5-HTTLPR polymorphism of the serotonin transporter gene predicts non-remission in major depression patients treated with citalopram in a 12 -weeks follow up study. J Clin Psychopharmacol 2003;23:563567.

18 Kim DK, Lim SW, Lee S, Sohn SE, Kim S, Hahn CG, Carroll BJ: Serotonin transporter gene polymorphism and antidepressant response. Neuroreport 2000;11:215-219.

19 Yoshida K, Ito K, Sato K, Takahashi H, Kamata M, Higuchi H, Shimizu T, Itoh K, Inoue K, Tezuka T, Suzuki T, Ohkubo T, Sugawara $\mathrm{K}$, Otani K: Influence of the serotonin transporter gene-linked polymorphic region on the antidepressant response to fluvoxamine in Japanese depressed patients. Prog Neuropsychopharmacol Biol Psychiatry 2002;26: 383-386.

-20 Heils A, Teufel A, Petri S, Stober G, Riederer P, Bengel D, Lesch KP: Allelic variation of human serotonin transporter gene expression. J Neurochem 1996;66:2621-2624.

21 Heinz A, Jones DW, Mazzanti C, Goldman D, Ragan P, Hommer D, Linnoila M, Weinberger DR: A relationship between serotonin transporter genotype and in vivo protein expression and alcohol neurotoxicity. Biol Psychiatry 2000;47:643-649.
22 Lesch KP, Balling U, Gross J, Strauss K, Wolozin BL, Murphy DL, Riederer P: Organization of the human serotonin transporter gene. J Neural Transm Gen Sect 1994;95: 157-162.

23 Mann JJ, Huang YY, Underwood MD, Kassir SA, Oppenheim S, Kelly TM, Dwork AJ, Arango V: A serotonin transporter gene promoter polymorphism (5-HTTLPR) and prefrontal cortical binding in major depression and suicide. Arch Gen Psychiatry 2000;57: 729-738.

24 Jacobsen LK, Staley JK, Zoghbi SS, Seibyl JP, Kosten TR, Innis RB, Gelernter J: Prediction of dopamine transporter binding availability by genotype: a preliminary report. Am J Psychiatry 2000;157:1700-1703.

25 Shioe K, Ichimiya T, Suhara T, Takano A, Sudo Y, Yasuno F, Hirano M, Shinohara M, Kagami M, Okubo Y, Nankai M, Kanba S: No association between genotype of the promoter region of serotonin transporter gene and serotonin transporter binding in human brain measured by pet. Synapse 2003;48: 184-188.

-26 Serretti A, Artioli P, Quartesan R: Pharmacogenetics in the treatment of depression: pharmacodynamic studies. Pharmacogenet Genomics 2005;15:61-67.

27 Smits KM, Smits LJ, Schouten JS, Stelma FF, Nelemans P, Prins MH: Influence of SERT$\mathrm{PR}$ and STin2 in the serotonin transporter gene on the effect of selective serotonin reuptake inhibitors in depression: a systematic review. Mol Psychiatry 2004;9:433-441.

28 Durham LK, Webb SM, Milos PM, Clary $\mathrm{CM}$, Seymour AB: The serotonin transporter polymorphism, 5-HTTLPR, is associated with a faster response time to sertraline in an elderly population with major depressive disorder. Psychopharmacology (Berl) 2004; 174:525-529.

-29 Kim H, Lim SW, Kim S, Kim JW, Chang YH, Carroll BJ, Kim DK: Monoamine transporter gene polymorphisms and antidepressant response in Koreans with late-life depression. JAMA 2006;296:1609-1618.

>30 Taylor MJ, Sen S, Bhagwagar Z: Antidepressant response and the serotonin transporter gene-linked polymorphic region. Biol Psychiatry 2010;68:536-543.

> 31 Joo EJ, Joo YH, Hong JP, Hwang S, Maeng SJ, Han JH, Yang BH, Lee YS, Kim YS: Korean version of the diagnostic interview for genetic studies: validity and reliability. Compr Psychiatry 2004;45:225-229.

32 Hamilton M: Development of a rating scale for primary depressive illness. Br J Soc Clin Psychol 1967;6:278-296.

-33 Kim JH, Choi SW, Joe SH, Ha TH, Yoo HJ, Choi JE, Cha B, Ha K: Reliability and validity of the Korean version of UKU-SERS-Pat in patients with bipolar disorder. Nord J Psychiatry 2008;62:496-502. 
34 Keller MB: Past, present, and future directions for defining optimal treatment outcome in depression: remission and beyond. JAMA 2003;289:3152-3160.

- 35 Yu YW, Tsai SJ, Chen TJ, Lin CH, Hong CJ: Association study of the serotonin transporter promoter polymorphism and symptomatology and antidepressant response in major depressive disorders. Mol Psychiatry 2002;7:1115-1119.

-36 Kunugi H, Hattori M, Kato T, Tatsumi M, Sakai T, Sasaki T, Hirose T, Nanko S: Serotonin transporter gene polymorphisms: ethnic difference and possible association with bipolar affective disorder. Mol Psychiatry 1997;2:457-462.

-37 Nakamura M, Ueno S, Sano A, Tanabe H: The human serotonin transporter gene linked polymorphism (5-HTTLPR) shows ten novel allelic variants. Mol Psychiatry 2000;5:32-38.

38 Gelernter J, Kranzler H, Cubells JF: Serotonin transporter protein (SLC6A4) allele and haplotype frequencies and linkage disequilibria in African- and European-American and Japanese populations and in alcohol-dependent subjects. Hum Genet 1997; 101:243-246.

-39 Bellivier F, Henry C, Szoke A, Schurhoff F, Nosten-Bertrand M, Feingold J, Launay JM, Leboyer M, Laplanche JL: Serotonin transporter gene polymorphisms in patients with unipolar or bipolar depression. Neurosci Lett 1998;255:143-146.

40 Fredman SJ, Fava M, Kienke AS, White CN, Nierenberg AA, Rosenbaum JF: Partial response, nonresponse, and relapse with selective serotonin reuptake inhibitors in major depression: a survey of current 'next-step' practices. J Clin Psychiatry 2000;61:403408.

41 Anderson IM: Selective serotonin reuptake inhibitors versus tricyclic antidepressants: a meta-analysis of efficacy and tolerability. J Affect Disord 2000;58:19-36.

42 Hachisu M, Ichimaru Y: Pharmacological and clinical aspects of fluvoxamine (depromel), the first selective serotonin reuptake inhibitor approved for clinical use employed in Japan. Nihon Yakurigaku Zasshi 2000; 115:271-279.
43 Srisurapanont M: Response and discontinuation rates of newer antidepressants: a metaanalysis of randomized controlled trials in treating depression. J Med Assoc Thai 1998; 81:387-392.

44 Lee BT, Ham BJ: Serotonergic genes and amygdala activity in response to negative af fective facial stimuli in Korean women Genes Brain Behav 2008;7:899-905.

45 Gelernter J, Cubells JF, Kidd JR, Pakstis AJ, Kidd KK: Population studies of polymorphisms of the serotonin transporter protein gene. Am J Med Genet 1999;88:61-66.

46 Wilkie MJ, Smith G, Day RK, Matthews K, Smith D, Blackwood D, Reid IC, Wolf CR Polymorphisms in the SLC6A4 and HTR2A genes influence treatment outcome following antidepressant therapy. Pharmacogenomics J 2009;9:61-70.

47 Reimherr F, Amsterdam J, Dunner D, Adler L, Zhang S, Williams D, Marchant B, Michelson D, Nierenberg A, Schatzberg A, Feldman P: Genetic polymorphisms in the treatment of depression: speculations from an augmentation study using atomoxetine. Psychiatry Res 2010;175:67-73.

48 Kirchheiner J, Nickchen K, Sasse J, Bauer M, Roots I, Brockmoller J: A 40-basepair VNTR polymorphism in the dopamine transporter (DAT1) gene and the rapid response to antidepressant treatment. Pharmacogenomics 2007;7:48-55.

49 Dogan O, Yuksel N, Ergun MA, Yilmaz A Ilhan MN, Karslioglu HE, Koc A, Menevse A: Serotonin transporter gene polymorphisms and sertraline response in major de pression patients. Genet Test 2008;12:225231.

50 Damberg M: Transcription factor AP-2 and monoaminergic functions in the central nervous system. J Neural Transm 2005;112: 1281-1296.

$51 \mathrm{Hu}$ X, Oroszi G, Chun J, Smith TL, Goldman D, Schuckit MA: An expanded evaluation of the relationship of four alleles to the level of response to alcohol and the alcoholism risk Alcohol Clin Exp Res 2005;29:8-16.
52 Lipsky RH, Hu XZ, Goldman D: Additional functional variation at the SLC6A4 gene. Am J Med Genet B Neuropsychiatr Genet 2009; 150B:153.

53 Wendland JR, Moya PR, Kruse MR, RenPatterson RF, Jensen CL, Timpano KR, Murphy DL: A novel, putative gain-of-function haplotype at SLC6A4 associates with obsessive-compulsive disorder. Hum Mol Genet 2008; 17:717-723.

54 Bonvicini C, Minelli A, Scassellati C, Bortolomasi M, Segala M, Sartori R, Giacopuzzi M, Gennarelli M: Serotonin transporter gene polymorphisms and treatment-resistant depression. Prog Neuropsychopharmacol Biol Psychiatry 2010;34:934-939.

-55 Braganca J, Eloranta JJ, Bamforth SD, Ibbitt JC, Hurst HC, Bhattacharya S: Physical and functional interactions among AP-2 transcription factors, p300/CREB-binding protein, and CITED2. J Biol Chem 2003;278: 16021-16029.

56 Schosser A, Kasper S: The role of pharmacogenetics in the treatment of depression and anxiety disorders. Int Clin Psychopharmacol 2009;24:277-288.

57 Baumann P: Pharmacology and pharmacokinetics of citalopram and other SSRIs. Int Clin Psychopharmacol 1996;11(suppl 1):511.

58 Aronson S, Delgado P: Escitalopram. Drugs Today (Barc) 2004;40:121-131

59 Rao N: The clinical pharmacokinetics of escitalopram. Clin Pharmacokinet 2007;46: 281-290.

60 Baumann P, Rochat B: Comparative pharmacokinetics of selective serotonin reuptake inhibitors: a look behind the mirror. Int Clin Psychopharmacol 1995;10(suppl 1):15-21.

-61 Nierenberg AA, Farabaugh AH, Alpert JE, Gordon J, Worthington JJ, Rosenbaum JF, Fava M: Timing of onset of antidepressant response with fluoxetine treatment. Am J Psychiatry 2000;157:1423-1428.

62 Nierenberg AA, McLean NE, Alpert JE, Worthington JJ, Rosenbaum JF, Fava M: Early nonresponse to fluoxetine as a predictor of poor 8-week outcome. Am J Psychiatry 1995; 152:1500-1503. 